\title{
Whatever happened to silence?
}

\section{John Launer}

Silence used to be integral to medicine. It now seems to be disappearing. A generation or two ago, hospital wards were often as quiet as places of worship. Doctors proceeded along the beds in ceremonial calm, and a sister or charge nurse would reprimand any nurse whose voice was raised above a murmur. Today, the sound environment has deteriorated badly in many places. All day and night, electronic machines bleep and whirr, alarms go off constantly, trolleys clatter and squeak, and staff banter with each other. As studies show, noise in some hospitals has now reached truly problematical levels, impairing patients' rest and sleep, and presumably their health as well. ${ }^{12}$

Silence is disappearing from medicine in other ways too. In the past, it was common for doctors to make careful use of silence in their conversations with patients, sometimes for five or ten seconds at a time. This would encourage quiet reflection by both parties, and allow thoughts and feelings to emerge gently. The tradition continues in some forms of psychotherapy and counselling, in palliative care, and among a minority of general practitioners and psychiatrists. There are also some national cultures that have maintained the practice: in Japan, for example, short respectful silences shared between doctor and patient are still common. However, in much of the medical world, silence in clinical encounters seems to have given way to a very different kind of discourse: relentless inquiry and uninterrupted explanations. The factors leading to this probably include increased workload, the volume of information that has to be elicited and imparted in every consultation, along with the ubiquity of computers, templates, algorithms and guidelines. Educational approaches such as shared decision-making may have accelerated the process by emphasising the cognitive aspects of clinical encounters, rather than on creating the right emotional tone in the first place.

A new book about silence sheds some fascinating light on the subject, and points towards what we might do to redress matters. Called 'The Silences of Science', ${ }^{3}$ it focuses on communications by scientists, but has lessons for medicine too. As

Correspondence to Dr John Launer, Health Education England, London WC1H 5DN, UK; johnlauner@aol.com the editors Felicity Mellors and Stephen Webster point out, gaps, pauses and lacunae are an essential and meaningful part of all human communication. Each conversation begins in silence, and ends in it. Whenever someone speaks, someone else has to keep silent in order to listen, either by choice or as the result of unequal power. Every spoken or written statement implies other utterances that have remained unexpressed: perhaps something has been intentionally concealed, or remained unconscious. Silence is everywhere, and we need to become more aware of it and how it operates.

\section{SILENCE AND BEING SILENCED}

Mellor and Webster offer a useful typology of silences (see table 1). They base this on whether someone's locus of control is internal (choosing to be silent) or external (being silenced), and if the silence helps communication or hinders it. Some of their examples are taken from communal contexts, like the silences required in libraries or imposed by censorship, but the categories also apply to one-to-one encounters. They can help us to identify how we each employ silence to evoke closeness or protect ourselves from it, and to obstruct or ease others in their self-expression.

Drawing on ideas from the book, I suggest there are three key aspects of silence that clinicians and medical educators need be aware of (see box 1). First, it is possible that some assertive forms of communication used nowadays may have the opposite effects to the ones intended - and effectively silence patients. Conversations that are ostensibly aimed at gathering information or exploring views may be so rapid and forceful that they negate both. This risk may be compounded by the wider context, including the lack of privacy, and continual interruptions by third parties. Restoring more silence to medical conversations, both in our speech and in the environment, might allow patients to think at their own natural pace, with potential benefits like being able to give fuller histories or to manage their own conditions better.

Next, silence and exchanging information need to complement each other, especially when serious illness is present. Much of the literature on cancer treatment and breaking bad news, for example, suggests that clinicians are often not very good either at imparting complex and distressing facts, or at creating the right conditions for patients to absorb these $e^{4-6}$ Doing both competently means knowing how to balance speech and silence, so that patients can take in distressing information properly and respond in their own time. Clinicians also need to learn how to calibrate their conversations in response to the cognitive and emotional requirements of each situation, and to the individual patient.

\section{COMPASSIONATE SILENCE}

We also need to ask the question: what is silence meant to express? In a paper in the Journal of Palliative Medicine, Anthony Back and his colleagues identify three different kinds of silence in clinical consultations. They call these 'awkward', 'invitational' and 'compassionate' silences. ${ }^{7}$ Well-meaning physicians, they point out, may sometimes think they are using silence as an effective behavioural technique, while the patient only feels a sense of awkwardness, and interprets the silence as judgement, ambivalence, disapproval or withholding. Invitational silence, by contrast, conveys more empathy. It allows both patient and doctor to digest everything that has been discussed so far and decide where to take the conversation next. Back et al relate this kind of silence to mindfulness practice, where practitioners consciously foster their capacity for attention, curiosity and presence in the moment. ${ }^{8}$

Beyond this, the authors of the paper invite doctors to regard silence as simply one expression of a compassionate state of mind. Referring to Eastern contemplative traditions, they explain how silence is inseparable from awareness of breath and body, careful speech, and an attitude of respect, and stillness. 'The ability to actualize mindful, compassionate silence' they write "can enable a clinician to shift from using silence, to making space for silence to emerge as a way to affirm mutual respect

Table 1 Types of silences with examples (adapted from Mellor and Webster ${ }^{3}$ )

\begin{tabular}{lll}
\hline & Helping communication & Hindering communication \\
\hline Internal (being silent) & Silent retreats & Conflict avoidance \\
& Intimacy & Protecting privacy \\
External (being silenced) & Libraries & Censorship \\
& Religious services & Official secrets legislation \\
\hline
\end{tabular}




\section{Box 1 Key aspects of silence in medical settings}

1. Speech and noise can have silencing effects on others

2. Silence and giving information are complementary

3. Silence arises naturally from a compassionate attitude

and understanding.' According to this view, silence is not merely something we should learn to apply in order to attain particular objectives. It is a spontaneous expression of 'being with' other people, in every sense.

Competing interests None declared.

Provenance and peer review Commissioned; internally peer reviewed.

(c) Article author(s) (or their employer(s) unless otherwise stated in the text of the article) 2018. All rights reserved. No commercial use is permitted unless otherwise expressly granted.
3 Mellor F, Webster S. The Silences of Science: Gaps and Pauses in the Communication of Science. London: Routledge, 2017.

4 Gilmour Hamilton C. The silenced subject: oral history and the experience of cancer research. In: Mellor F, Webster S, The Silences of Science: Gaps and Pauses in the Communication of Science. London: Routledge, 2017:152-71.

5 Friedrichsen MJ, Strang PM, Carlsson ME. Breaking bad news in the transition from curative to palliative cancer care--patient's view of the doctor giving the information. Support Care Cancer 2000:8:472-8.

To cite Launer J. Postgrad Med J 2018;94:189-190.

Postgrad Med J 2018;94:189-190.

doi:10.1136/postgradmedj-2018-135629

6 Hanratty B, Lowson E, Holmes L, et al. Breaking bad news sensitively: what is important to patients in their last year of life? BMJ Support Palliat Care 2012;2:24-8.

\section{REFERENCES}

1 Darbyshire JL, Young JD. An investigation of sound levels on intensive care units with reference to the WHO guidelines. Crit Care 2013;17:R187.

2 Sasso L, Bagnasco A, Aleo G, et al. Editorial: Noise on hospital wards--what have we learned? J Clin Nurs 2016;25:891-3. 